\title{
Sobre o Espaço Natural e a Forma Urbana. à guisa de posfácio
}

\author{
Geraldo G. Serra
}

\begin{abstract}
As dificuldades da pós-graduação e da elaboração da tese A abordagem científica das questōes formais do espaço natural e urbano. A especificidade dos estudos urbanos e o rigor terminológico. Instrumentos, técnica e tecnologia. Projeto e construçāo. A possibilidade dos juízos de valor sobre as adaptaçōes espaciais e suas aglomeraçōes. As adaptaçōes espaciais e a sua simulação: a operação com modelos.
\end{abstract}

\section{Abstract}

Difficulties of the post-graduation studies and of the thesis work. The scientific approach to the natural and urban space formal questions. Specificity of the urban studies and terminological rigor. Instruments, technique and technology Design and building. The possibility of a value judgment about spatial adaptations and its agglomerations. The spatial adaptations and its simulation: models operation.
Artigo elaborado com base na Tese de Doulorado "O Espaço Natural e a Forma Urbana" apresentada em maio de 1985

Orientador: Prof. Dr. Ariosto Mila 


\section{Introdução}

O presente texto versa sobre a tese de doutorado que defendi em 1985 na FAU. Além de resumir os aspectos fundamentais daquela tese, apresenta considerações resultantes do debate com meus alunos e de meditações ulteriores. Essas meditaçōes foram provocadas por algumas idéias sugeridas pelo trabalho de pesquisa e que não pude desenvolver durante o meu doutorado e. também, pela confrontação das conclusões da tese com outros cenários e com outras idéias.

Em 1987. publiquei o livro O espaço natural e a forma urbana. cujo texto, a menos de pequenas revisões, era a minha tese de doutorado. Alguns anos depois publiquei o livro Urbanização e Centralismo Autoritário. baseado em minha tese de livre-docência. A disciplina Obras Urbanas, que venho lecionando na pós-graduação da FAU, toma esses dois livros como textos básicos. Pude, assim, ao longo de diversos cursos discutir essas idéias com meus alunos e ouvir suas dúvidas e críticas. Agora, ao abordar outra vez essa temática, o faço dentro da perspectiva crítica que esses debates propiciaram.

Este texto foi escrito para pós-graduandos em Arquitetura e Urbanismo. Nāo pretende acrescentar muito àquilo que já foi dito no livro. Pretende, isso sim, fornecer ao pós-graduando um depoimento franco sobre as dificuldades que o desenvolvimento de uma tese de doutorado apresenta, principalmente quando o seu autor está realmente imbuído da intenção de acrescentar um pequeno tijolo ao edifício do conhecimento. Tenho a pretensão de que ele possa ser útil para aqueles que, estando embrenhados na selva dos conceltos e dos dados, sintam-se um pouco perdidos. É comum que nessa luta apresente-se com freqüência a tentação de mudar de tema (ou de orientador!) ou se instale a dúvida sobre a capacidade de concluir o caminho iniciado

A pós-graduaçāo está, entre nós, dividida em duas etapas: o mestrado e o doutorado. Ora, dadas as características com que essas etapas estāo definidas, o que se pede ao mestrando é que se torne um pesquisador e do seu trabalho se espera que esgote o conhecimento em determinada área, ligada ao objeto de sua dissertação. Se não parece possivel fazer isso é porque o objeto é grande demais ou excessivamente ambicioso e deve ser melhor definido e cırcunscrito. O doutorando é já um pesquisador e da pesquisa se espera o novo, o original... Tenho insistido, durante anos, que o produto da pesquisa é uma descoberta ou uma invenção. Admito que, no caso de disciplinas ligadas à tecnologia e às artes, a invenção possa ser apenas uma inovação. Mas, em qualquer caso, a tese de doutorado não pode ser uma dissertação por maior e mais completa que o seja, pois o dissertar sobre determinado tema não implica necessariamente inovação.

Por vezes tenho estado em bancas em que se pede ao doutorando que mostre qual é a sua hipótese e onde está a demonstração. Ora, a tese, apesar do nome, não precisa ser um silogismo, embora deva ser lógica. Na verdade é mesmo absurdo pedir de um trabalho científico, pela própria natureza indutivo, que apresente uma dedução cabal da sua verdade, como se se tratasse de um teorema. A lógica deve presidir todas as operaçōes com proposições. mas o método científico pretende apenas induzir proposições gerais de um conjunto suficientemente amplo. mas necessariamente finito, de observaçōes.

Sobre o conteúdo de inovação das teses é preciso reconhecer que, às vezes, embora no global o conhecimento novo produzido nāo pareça muito importante, pode ocorrer que para atingir aquela conclusão se tenha desenvolvido um grande número de pequenos passos, todos eles inovadores. A inovação pode 
estar na metodologia ou no desenvolvimento de uma taxionomia ou de uma terminologia mais adequada.

Na nossa época, o avanço do conhecimento dá-se pelo trabalho coletivo de inúmeros pesquisadores, cuja condiçāo de cientista decorre da aceitação de um conjunto de regras sobre a verificaçāo impessoal dos resultados do seu trabalho, as quais o legitimam. Por isso, o isolamento é a forma que a barbárie assume na universidade moderna. A primeira daquelas regras diz que o pesquisador deve deixar absolutamente claras as suas fontes, os seus dados e os seus métodos, não por qualquer princípio ético abstrato, mas para que seja mais fácil à comunidade científica verificar os seus resultados, para rejeitá-los ou aceitá-los e, no devido tempo superá-los, fazendo assim com que o conhecimento avance.

Nos dias atuais, esse processo ganhou uma dinâmica extraordinária mercê das inovaçōes tecnológicas. Um ilustre colega me dizia em certa ocasião, querendo ironicamente referir-se ao atraso em que se encontrava determinada universidade estrangeira, que "lá, eles ainda lêem livros!" Está evidente que todo pesquisador deve ler muitos livros! Contudo, o que o meu amigo queria dizer é que nos encontramos num momento em que a rapidez do processo de inovação e de desenvolvimento do conhecimento é tal, que quando algo chega a ser editado na forma de livro, provavelmente já estaria superado. e que o pesquisador atualizado emprega o seu tempo de leitura lendo os periódicos da sua área. Ressalvado o evidente exagero dessas colocações, cabe lembrar que a "descoberta" da fusão nuclear a frio foi transmitida à comunidade científica por fax e rejeitada pela mesma comunidade por fax também. Nos tempos de Newton, quantos meses demorou Leibnitz para tomar conhecimento dos "Principia"? E agora, parece que alguns só lêem o "e-mail" pois lhes repugnam as "hard copies" de qualquer tipo!

\section{As Relações Formais do Espaço Natural e da Estrutura Urbana}

A hipótese básica sobre a qual trabalhei no meu doutorado afirmava que existem relações de determinação entre a forma do espaço natural e a forma urbana ali construída. Como havia eu chegado à tal hipótese? Trata-se de algo óbvio ou evidente?

Uma hipótese é uma idéia explicativa do real, a qual ainda nāo podemos afirmar ser verdadeira, pois o método científico exige a demonstração de que em muitos casos observados por comparação com outros, ditos de controle, eliminadas as coincidências e fatores acidentais (na medida do possivel!) aquela proposição é verdadeira. Sobre essa questão, remeto o leitor interessado às obras de Khun, Bunge, Vieira Pinto e Vargas. Para os que preferem se abeberar nos textos básicos, recomendo Hume.

A idéia de que a forma das cidades estava profundamente determinada pela forma do espaço natural onde elas haviam sido construídas, me havia ocorrido pela observação, ao longo de muitos anos de trabalho de dezenas de diferentes cidades brasileiras. Havia medrado na cesura entre esses muitos objetos concretos (Bunge) e os textos onde eu procurava explicaçōes para a variedade na similaridade. De um lado os textos pareciam procurar a regularidade no meio da diversidade, de outro lado o que nos interessava era exatamente essa diversidade.

Em geral, o pesquisador pretende afirmar que encontrou uma proposição ou um conjunto de proposições, que são verdadeiras para inúmeros objetos 
concretos examinados e que, em decorrência, sāo também válidas para todos os demais objetos da mesma espécie. Essa proposição ou conjunto de proposições é, portanto, uma teoria ou um modelo daqueles objetos concretos e de suas relações. Ora, a maioria esmagadora dos textos sobre a cidade foram escritos por pesquisadores das ciências sociais. Seu trabalho busca encontrar padrões na dinâmica das forças sociais construtoras da cidade. Forma para eles é modo de existência e não "contorno externo dos objetos" como diria Locke. Estão preocupados com o que há de comum entre as cidades, enquanto nós, que lidamos com a forma urbana, estamos preocupados com o que há de diferente entre elas.

As dificuldades, por conseguinte, radicavam em camadas mais profundas do fenômeno da aglomeração das adaptaçōes espaciais construídas pelas sociedades humanas. Originavam-se na própria definição do objeto da pesquisa e da terminologia adequada a essa investigação.

Um bom exemplo dessa dificuldade está em La question urbaine. livro obrigatório nas nossas bibliografias nos últimos 10 ou 15 anos. A divisão dos "elementos" da cidade naqueles destinados à produção, ao consumo, à troca e às funções simbólicas ou de gestão, constitui uma teoria que explica o que há de comum a todas as aglomerações. Ora, como nós estamos preocupados com a forma dessas aglomeraçōes, nos interessa saber exatamente porque elas são diferentes! O objetivo, portanto. é a determinação dos fatores que determinam formas urbanas diferentes. Os arquitetos e urbanistas querem saber como é gerada a forma urbana, o "contorno externo" da cidade, e como podem intervir na construção dessa forma. E essa forma, não é o modo de existir, mas aquilo que se percebe no espaço.

Formular uma boa hipótese de trabalho costuma ser mais difícil do que mostrar o seu valor de verdade! Na tentativa de expressar. para mim mesmo e para os meus colegas. uma hipótese que ainda não estava clara, comparava eu Jundiai com Itu, e perguntava se era possivel que uma pessoa se equivocasse, isto é, que estando em Jundiaí pensasse estar em Itu. e vice-versa. A resposta é obviamente negativa. pois tratam-se de duas formas espaciais completamente diferentes. Contudo, as teorias sócioeconômicas disponíveis. inclusive a de Castells, pareciam indicar que se tratavam de dois objetos senão idênticos. pelo menos muito parecidos. Ora, apesar das evidentes similaridades no seu desenvolvimento. o que realmente tornava esses dois objetos completamente diversos era a sua forma. o seu contorno externo. E esta me parecia profundamente determinada pelos sítios em que haviam sido erguidas aquelas cidades, completamente diversos.

Era preciso ainda reconhecer que, longe da pretensāo de criarmos espaços, o que realmente fazemos é promover adaptaçōes num espaço natural dado ou como acontece na imensa maioria das vezes, readaptar espaços adrede adaptados. Um lote ou mesmo uma gleba urbana são espaços adaptados, pois situam-se em meio a uma grande aglomeração de obras de infra-estrutura viária que lhe conferem forma.

Embora para muitos essa proposição possa parecer óbvia, o fato é que nāo é fácil prová-la. Além disso, a tentativa de comprovar essa hipótese levou-me a inúmeros outros estudos. que em muitos casos pareciam tão ou mais importantes do que a questão central sobre a qual eu me debruçava. Rapidamente percebi que a terminologia utilizada nos estudos urbanos era uma algaravia espantosa. decorrente de serem os diversos autores originados em áreas do conhecimento muito diferentes. Economistas, geógrafos, sociólogos, psicólogos e engenheiros utilizavam as próprias terminologias, em geral cunhadas 
para encontrar o padrāo entre inúmeros fenômenos urbanos diversos, e quase nunca preocupados com a forma desses objetos, com aquilo que era peculiar a cada objeto concreto considerado.

\section{A Especificidade dos Estudos Urbanos e a Questão Terminológica}

A bibliografia sobre o fenômeno urbano faz por vezes duvidar da especificidade do objeto e da ciência que dele se ocupa. Preocupados com o fracasso bastante óbvio do urbanismo neste século, quero dizer, com a incapacidade dos planos urbanísticos gerarem espaços mais adequados às atividades humanas, os arquitetos e urbanistas optaram por duas soluçōes diferentes. A primeira foi a do planejamento urbano, entendido como uma atividade pertencente a um campo mais amplo chamado planejamento, e que em última análise pretende ordenar a açāo humana para determinados objetivos. A segunda, a do "urban design" recua prudentemente para uma definição mais restrita da profissāo do arquiteto e do urbanista, abarcando a operação de modelos das cidades ou de suas partes. entendidas como construçōes físicas.

Ora, de um lado é evidente que o objeto de estudo dos urbanistas é bastante específico: as aglomeraçōes de adaptações espaciais destinadas a abrigar as pessoas e seus produtos. O questionamento da especificidade parece referirse, portanto, à definiçāo dos aspectos do objeto considerados relevantes na construção dos seus análogos materiais, às abordagens e métodos de investigaçāo e mesmo ao tipo de conclusāo produzida. ou que se parece intentar produzir. De fato, aqueles que optaram pelo planejamento, rapidamente enredaram-se num grande e variado número de campos do conhecimento e de ciências diversas, principalmente as Ciências Sociais, particularmente a Economia, mas também a Psicologia, a Estatística, a Demografia, etc... Por volta dos anos 60, muitos profissionais e pesquisadores acharam indispensável completar a sua formaçāo freqüentando cursos dessas ciências, muitas delas em plena crise de identidade, como era o caso da Geografia. Essas ciências têm métodos diferentes e preocupam-se com aspectos diversos das aglomerações urbanas. Todo esse esforço acabou por gerar a sensação de que os estudos urbanos, como o tinham sempre concebido os arquitetos e urbanistas, nāo possuiam especificidade conceitual ou metodológica.

Para comprovar-se com facilidade essa situaçāo, basta considerar-se a confusāo babélica das terminologias utilizadas e dos cursos de formaçāo de arquitetos-urbanistas. As inúmeras reformas curriculares, raras em outras profissōes mas muito freqüentes nas escolas de arquitetura e de urbanismo, parecem indicar uma dificuldade muito grande. nāo em conceber novos currículos pois esses abundam, mas para definir com precisão o que é realmente necessário estudar-se para tornar-se um arquiteto-urbanısta. Uma relação de temas de pesquisa ou denominaçōes de dissertaçōes e teses na pós-graduaçāo mostra uma impressionante amplitude de interesses e uma capacidade leonardiana. Em certo momento, pareceu-me mesmo que talvez isso pudesse indicar uma qualidade histórica: a de herdeiros da tradição renascentista, num mundo de especializaçāo extremada.

Por causa disso, tudo indicava ser necessário iniciar a minha investigaçāo por uma pesquisa rigorosa dos conceitos, das taxionomias e das terminologias: construir os instrumentos de trabalho. Em outros ramos do conhecimento - na Química, na Fisica ou na Biologia - pode-se encontrar dificuldades desse tipo, mas jamais na dimensāo babélica com que aparece nos estudos urbanos. 


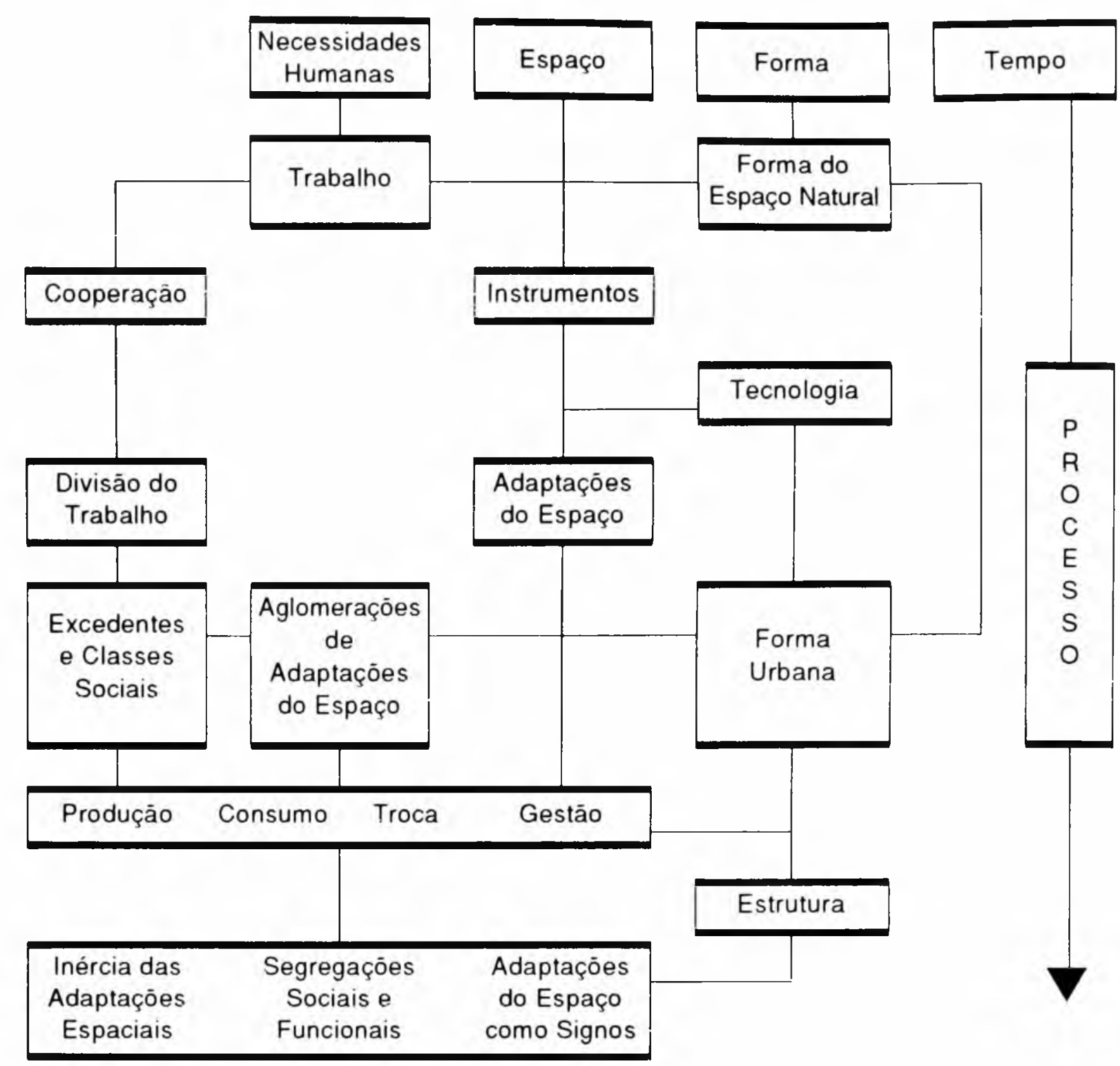

O esquema acima mostra os principais conceitos básicos e derivados. assim como as suas relaçōes, como desenvolvidos e utilizados na tese "O espaço natural e a forma urbana"

Tomei alguns conceitos como básicos, isto é, conceitos que eu discutiria e comentaria, mas não teria a pretensão de definir. Alguns deles são do tamanho da Filosofia, como "espaço" e "tempo" Outros foram tomados como básicos porque se supõe definidos por outros ramos do conhecimento não cabendo no âmbito de uma tese sobre Arquitetura e Urbanismo defini-los. Enquadram-se neste caso os conceitos de "necessidades humanas" de "trabalho" e de "instrumento" À medida em que me aproximava dos conceitos realmente arquitetônicos e urbanísticos. me preocupava mais a construção e mesmo a definição dos conceitos. Caminhei, portanto, de conceitos como "produção" "consumo" "troca" e "gestāo" para as "adaptaçōes espaciais" e para as "aglomeraçōes de adaptações espaciais" até finalmente chegar à "forma" à "estrutura" e ao "sistema" Dentro do que me foi possivel. procurei cartesianamente evitar usar conceitos que não houvessem sido adrede definidos.

Apesar desse esforço, não me foi possivel evitar alguns desvios por terras ignotas, tais como a Semiótica e a Topologia. Na Semiótica me pareceu necessário ir buscar uma melhor compreensão das funções simbólicas das adaptaçōes espaciais dedicadas à gestāo. Na época havia um certo exagero na literatura, principalmente a de origem francesa, sobre a questão do poder. A dinâmica do poder. uma espécie de broto tardio (e um tanto mediocre!) da teoria urbana marxista, gerava todo ano um novo livro, cuja exegese impunha- 
se aos pobres pós-graduandos. Se ganharia mais, relendo o texto do próprio Marx sobre a cooperação ou Engels tratando da condição da classe operária na Inglaterra do século 19 !

Felizmente não havia (ou não era do meu conhecimento!) uma Semiótica marxista! Depois de investir muito nas tríades peircianas, acabei na Semântica de Adam Shaff que, esta sim, me ajudou bastante na construçāo dos conceitos e na compreensão do significado das obras urbanas.

A Topologia parece indispensável para a compreensão da operação com análogos materiais, tão típica do trabalho de arquitetos e urbanistas. Muito tempo depois, ainda faço o exercício de designar uma folha de papel em branco como sendo um mapa de São Paulo, e minimalisticamente, acrescentar a ela uma direção, um sentido, uma escala e um ponto para referenciar todos os demais pontos do espaço paulistano. De outra forma, como entender a correspondência biunívoca entre os pontos dos mapas, das plantas e das maquetes e o espaço ou obra que simbolizam?

\section{O Instrumento, a Técnica e a Tecnologia}

$\mathrm{Na}$ busca frustrante por algo que nos distinga dos animais, os antropólogos passaram da racionalidade, à oposiçāo do polegar aos demais dedos e daí, para o uso de instrumentos. Como nāo é nosso objeto saber se algo realmente nos distingue dos nossos irmãos símios, fiquemos com o fato incontestável de que a ação humana sobre o espaço é sempre intermediada por algum tipo de objeto que facilita a operação. Esses objetos são os instrumentos. Uma esplêndida alegoria à descoberta do instrumento é apresentada no antológico filme "2001 - Uma odisséia no espaço" quando o hominídio, após a vitória sobre seu irmão, propiciada pela utilização de um osso como arma, percebe a importância da descoberta (invenção. inovaçāo?).

A cultura, assim, seria um processo de criaçāo e manufatura de conjuntos cada vez maiores de instrumentos cada vez mais complexos, processo esse que se confunde com o trabalho cooperativo da espécie humana sobre o espaço para atender as suas necessidades. $E$, realmente, é comum que antropólogos e catálogos dos museus refiram-se a culturas indigenas ou pretéritas como determinados conjuntos de instrumentos.

De outro lado, a técnica, parte importante de qualquer cultura, consiste num conjunto de regras para operação eficiente dos instrumentos que a constituem. Com a multiplicação dos instrumentos. foi possivel classificá-los, com suas regras, em campos específicos. O conjunto dessas técnicas, ou determinados subconjuntos delas, assim como o estudo dos seus modos de produção se denomina, tecnologia.

O desenvolvimento dessas questōes era particularmente importante, pois, as formas das adaptações espaciais e de suas aglomeraçōes vão depender da capacidade de determinado grupo humano. de modificar o seu ambiente. Esta é uma questão central na tese da determinação da forma urbana pelo espaço natural.

O conceito de forma do espaço natural, considera que essa forma está determinada nāo apenas pelas "rugosidades" naturais do relevo e da hidrografia, mas por todos os demais aspectos tais como o subsolo, o solo, o clima, a vegetação e a fauna. Para a construção dos seus instrumentos o homem trabalha dentro de um conjunto dado de materiais e condições. Produz com 
seu trabalho os instrumentos de que necessita, dentro de um conjunto de possibilidades definidas pelo espaço em que vive e trabalha.

As necessidades humanas não são meramente as biológicas, mas principalmente e cada vez mais, necessidades socialmente definidas. Os instrumentos criados para atenderem às suas necessidades socialmente definidas são por elas determinadas dentro das possibilidades contidas pelo espaço natural em que essa sociedade se desenvolve. A interação entre a sociedade e o espaço em que ela se desenvolve, isto é o trabalho, produz um conjunto de instrumentos e de regras para a sua utilização eficiente. num processo contínuo de interaçōes recíprocas entre a sociedade e o espaço, cujo produto é a cultura.

É absolutamente necessário que esses conceitos sejam entendidos dentro de um processo de interações dialéticas de determinações reciprocas. Somente ai podem eles ser entendidos como um sistema, autorizando os planejadores a falarem de abordagem sistêmica.

Embora todo e qualquer instrumento seja uma adaptação espacial, no contexto da arquitetura e dos estudos urbanos a ênfase recai sobre determinadas adaptações que se caracterizam tanto pela sua dimensão como pela sua imobilidade. Sendo esses instrumentos fixos. as suas aglomeraçōes podem também ser consideradas como adaptaçōes espaciais, construidas e em construçāo coletiva. E assim tambem os demaıs elementos de modificação da paisagem, tais como as rodovias, as ferrovias, os portos e aeroportos.

A cultura não e portanto um processo de preservação do meio ambiente, mas da sua adaptação às necessidades humanas. A luta que atualmente se trava pela "preservação do meio ambiente" freqüentemente se equivoca ao colocar como seu objetivo o restabelecimento das condiçōes naturais adrede existentes. Na verdade, a crítica ambientalista concentra-se na inadequação de determinadas adaptaçōes espaciais ou aglomeraçōes, às necessidades humanas. Essas adaptaçōes teriam sido construídas para atender objetivos parciais de determinados indivíduos ou grupos de indivíduos, contrapondo-se aos interesses mais gerais da sociedade.

A capacidade de promover adaptações espaciais cada vez maiores e cada vez em maior número e mais rapidamente. é uma decorrência do desenvolvimento dos instrumentos e das técnicas da sua construção. Ao conjunto dessas técnicas e instrumentos, denominamos tecnologia da construção. A construção do túnel 9 de Julho, em São Paulo, foi muito demorada e difícil, pois o movimento de terra era feito em carroças puxadas por animais. A conclusāo do túnel sob o rio Pinheiros. na mesma cidade, se faz rapidamente pois empregamos equipamentos pesados de enorme força motriz. A construção do Canal de Suez foi muito mais demorada e difícil do que a construçāo do túnel sob o Canal da Mancha, apesar de que este último é uma obra muito mais complexa do que Suez.

A tecnologia da construção engloba os instrumentos e as regras para a promoção de grandes adaptaçōes fixas no espaço natural. sempre com o objetivo de atender às necessidades humanas. Estas, contudo, nāo são consensuais. A aglomeração é o espaço do conflito. e o principal conflito diz respeito à apropriação do espaço e à promoção de adaptaçōes nele.

A forma das adaptações espaciaıs, e portanto das suas aglomeraçōes. é determinada pela forma do espaço natural porque é uma adaptação dele, porque é produzida por meio de uma tecnologia gerada no trabalho sobre ele e porque visa atender a necessidades socialmente definidas nele. Redundante- 
mente se dirá que se estabelecem entre os elementos desse sistema urbano relaçōes de interaçāo intensa no tempo, que denominamos processo urbano.

De cada processo urbano concreto emerge uma forma urbana, dentro da qual podemos identificar uma estrutura composta de elementos em interação, comuns a inúmeras outras aglomeraçōes, mas que é única, pois resulta da adaptação de um único espaço natural, com a utilização de tecnologias específicas num quadro cultural específico.

\section{Questões em Aberto}

Sem assumir compromisso com uma determinada agenda de trabalho, uma vez que outros caminhos (ou descaminhos!) me têm desviado desses assuntos, gostaria de elencar a seguir algumas questōes que ao longo da tese foram sendo abertas e que, por não se situarem na linha maior de atenção naquele momento, foram postergadas. Não as coloco como um plano de trabalho. nāo porque não me interessem, mas principalmente porque mereceriam a atenção de especialistas ou demandariam todo um longo plano de pesquisa para sua elucidação. Se alguém achar que pretendo insinuá-las aos jovens doutorandos, devo dizer diferentemente dos produtores cinematográficos, que essa insinuação não é acidental. mas deliberada: gostaria mesmo vê-las tratadas numa tese de doutorado.

\section{Projeto e construção}

Muitos arquitetos ficam um pouco confusos quando se thes pergunta se construíram determinado edifício e apressam-se a esclarecer que são apenas os autores do projeto. De outro lado, era e ainda é comum que o arquiteto americano diga que "construiu" determinado edifício.

Entre nós, o verbo construir não parece designar uma operaçāo técnica, mas sim comercial e financeira. Em determinado momento da história da profissāo do arquiteto no Brasil, a estratégia dos arquitetos parecia voltada para um acordo com os engenheiros civis, na qual se propunha que os primeiros somente projetassem e os segundos somente construissem. Felizmente não deu certo!

O que significam os verbos "projetar" e "construir" não apenas na prática profissional brasileira contemporànea ou no CREA. mas no contexto da produção das adaptações espaciais e de suas aglomeraçōes?

Em primeiro lugar, é necessário considerar que os aspectos comerciais da atividade do empresário da construçāo, do incorporador ou do empreiteiro de obras públicas, nada tem a ver com a atividade de construir. Exercem eles funções sociais respeitáveis e necessárias, mas não são construtores. Lidam com a compra e a venda de materiais e māo-de-obra ou do produto acabado, objeto do seu investimento. As inovaçōes tecnológicas da construção só lhes interessa quando seja passivel de monetarização. para a mediçāo da sua eficiência econômica. Ora. num país em que uma população marginal constitui um enorme "exercito industrial de reserva" permitindo manter o salarıo em niveis de subsıstência. nāo há qualquer razāo para interessarem-se por processos de industrialização ou pré-fabricação, que supostamente foram desenvolvidos por serem mais eficientes, mas que quando monetarizados num quadro de sub-remuneração do trabalho. são claramente "Ineficientes" 
Nesse quadro, a invenção e a descoberta de novos instrumentos e de novas técnicas, só adquirem sentido econômico quando configuram uma inovação a nivel do "marketing" Ora, o mercado está determinado por relaçōes culturais de dependência ou de globalização, isto é, as necessidades estāo sendo socialmente definidas pelo desejo de integração nos níveis e padrões de consumo observados nos países centrais, processo vulgarmente denominado "modernização" Daí a perplexidade e impotência com que se observa o recuo da grande arquitetura brasileira dos anos 40 , que atraía a atenção do mundo todo exatamente pela sua adequação ao nosso espaço natural, tanto na sua forma quanto na técnica de construção, para o "international style" dos pobres que ora se observa, e que evidentemente não interessa a mais ninguém.

A demanda real por habitação é óbvia, mas nossa sociedade não parece capaz de transformá-la na demanda efetiva dos que têm dinheiro para pagar por ela. Em determinado momento chegou-se a falar em financiar habitaçōes para a faixa de renda familiar de 0 a 3 salários mínimos. Ora, se o individuo ganha 0 evidentemente nāo pode ser financiado, pois não terá como retornar o empréstimo, e de qualquer maneira, nessas faixas de renda a necessidade não é "socialmente definida" mas biológica, eu diria, gastrointestinal. Decorre que também aí, torna-se patético o esforço por produzir casas mais baratas, quando o problema principal parece ser o crescimento da renda. Há muitos anos, em reunião no $I A B$, ouvi. revoltado. certo ministro de Estado dizer que o objetivo do Plano Nacional da Habitação não era produzir casas, mas empregos: hoje acho que ele estava certo! E como saneamento básico é o setor mais "mão-de-obra intensivo" talvez seja melhor nos concentrarmos nos esgotos!

\section{Julgamento de valor}

Como diria o Herr Prof. Kant: como é possivel a existência de juízos de valor sobre as adaptaçōes espaciais? É comum se dizer que esta obra é melhor do que aquela, que esta casa é bonita e que aquela outra é feia, que tal ou qual cidade é maravilhosa! De onde pode-se originar uma avaliação estética das adaptaçōes espaciais e de suas aglomeraçōes?

Percebo, evidentemente, que se trata de uma questão estética. Mas ela deveria ser respondida ao nivel de nossas teorias urbanas de hoje. Os sociólogos, economistas e geógrafos podem ignorá-la, pelo menos enquanto profissionais ou cientistas. mas os arquitetos e os urbanistas nāo podem fazer de conta que não estamos falando de forma e que sobre as formas das adaptações espaciais e suas aglomeraçōes sempre se fizeram juízos estéticos. A questão é colocada kantianamente para enfatizar que o problema não consiste no estabelecimento de regras sobre o belo, mas sim de investigar como uma estética se insere nos estudos do urbano.

O funcionalismo pretendeu que esses julgamentos estavam ligados à maior ou menor adequação de determinado instrumento à sua função. Nesse sentido um Boeing é uma obra de arte de grande valor. Aqui cabe lembrar o caso citado por Plekanov, do prato de madeira com baixo relevo, feito por certa tribo da América do Sul: o prato mais apreciado pela tribo era um cujos sulcos eram tão profundos que já haviam atravessado a espessura do prato, tornando-o inútil. Sobre a matéria, Elie Faure não deixa a menor dúvida: "La forme belle. qu'elle soit un arbre ou un fleuve, le seins d'une femme ou ses flancs, les épaules ou les bras d'un homme ou le crâne d'un dieu, la forme belle c'est la forme qui s'adapte à sa fonction" Se entendermos que a função da obra é o seu conteúdo, essa adequaçāo forma-conteúdo seria de fato um critério de 
juízo de valor estético no sentido hegeliano. A questão é qual seria o conteúdo da arquitetura.

Outra alternativa considera os julgamentos de valor ligados à adequação da forma do objeto ao material e à técnica empregada na sua execução. Aqui se pode aceitar o prato de Plekanov como uma obra de grande valor, apesar de que como prato é inútil. Ao nível da aglomeração - criaçāo coletiva ao longo de muito tempo - haveria uma estética ligada à sabedoria com a qual a forma do espaço natural foi compreendida e adaptada. A forma do espaço natural, como já vimos anteriormente, engloba nāo apenas o relevo e a hidrografia, mas todos os demais aspectos constitutivos do meio ambiente, aí incluídos os materiais disponiveis para a construçāo das adaptaçōes. A compreensāo e a adaptação dessa forma significa gerar outras formas pelo conhecimento da natureza do espaço natural e pelo desenvolvimento de técnicas a ele adequadas.

O significado das adaptaçōes espaciais e de suas aglomerações, componente fundamental na valoração estética das mesmas, não seria nesse caso o significado que o seu construtor ou construtores pretenderam Ihes dar Nāo seriam apenas as conotaçōes de poder, objeto de tantos estudos recentes. Seria alguma coisa menos acidental e relativa, e mais solidamente fundada na própria cultura, como expressa nas técnicas e na compreensão do espaço natural. empregadas na construçāo dessas adaptaçōes e de suas aglomerações.

\section{Operação com modelos}

Formular proposições sobre o mundo implica operar com símbolos verbais. Um conjunto de proposições inter-relacionadas pode constituir uma teoria. isto é, um modelo verbal explicando determinados aspectos do real. Se essas proposições forem substituídas por equações, teremos um modelo matemático.

Um projeto, no seu sentido mais amplo, é um conjunto de proposições verbais, equações matemáticas, desenhos ou outros análogos materiais, que pretendem representar uma adaptação a ser introduzida no espaço natural ou já adaptado. Tendo em vista o alto custo da construçāo dos instrumentos fixos, principalmente dos edifícios e das obras urbanas, considera-se indispensável construir um modelo tão exato quanto possível dessas obras, para que seja possivel avaliar-se o custo e os benefícios que a sua construção trará. Além disso, esses modelos permitem a programaçāo das açōes complexas que um trabalho essencialmente cooperativo, envolvendo um grande número de pessoas, certamente implica.

A sociedade humana vem produzindo adaptaçōes espaciais e aglomerações cada vez maiores e maıs complexas. Decorre que a importância da operação com modelos torna-se cada vez maior. A construção de adaptaçōes sıgnifica. de forma geral, a composição de materiais retirados do espaço natural, com o uso de instrumentos também dele originados para produzir um novo instrumento fixo, pela modificação das formas do espaço natural ou já adaptado, de modo que a nova forma construida atenda uma necessidade humana socialmente definida. Com o crescimento da importância dos modelos, a construção passa também a ser definida como a execuçāo de uma série de operações de acordo com as diretrizes do modelo. A nova forma construida estarla determinada, a priori, no modelo. Por conseguinte. a compreensāo da natureza da forma do espaço natural ou já adaptado, o entendimento profundo dos materiais e das técnicas de construção, elementos absolutamente essenciais na determinação da forma das novas adaptaçōes e da sua aglomeração, confor- 
mam o modelo, constituem o projeto e estão nele subjacentes ou explícitos. As operações de construção passam à condição de execução de um projeto, isto é, do agenciamento de materiais e técnicas numa seqüencia e numa disposição espacial por ele determinada. Por isso, a atividade de construir é cada vez mais uma operação essencialmente comercial, completamente desligada da técnica e cada vez mais dependente de consultores técnicos, estes sim donos do saber específico necessário.

De outro lado, a complexidade dos modelos análogos materiais, torna a sua operação em si mesma muito complexa, exigindo treinamento específico prolongado. O conhecimento de um programa de computação para apoio ao projeto e ao desenho é em si mesmo uma etapa árdua desse treinamento. $E$ saber desenhar já era uma tarefa árdua... A operação com modelos matemáticos do comportamento das estruturas é campo bastante difícil, exigindo muita dedicação do profissional. O número de sistemas incluídos nas atuais adaptações espaciais é de tal ordem e cresce tanto, que parecem, muitas vezes, as mais nítidas características da modernidade. Tudo isso vem compartimentando o saber específico. Nós não temos dúvida de que Michelangelo construiu boa parte da Catedral de São Pedro e de que Gaudi construiu a Sagrada Família. Mas quem construiu o World Financial Center? Foi Cesar Pelli? Ou o "general contractor"? Faz 10 anos que Richard Meyer trabalha no projeto da Paul Getty Foundation. em Los Angeles. Mas o que quer isso dizer? Ao que parece, que faz 10 anos que aquele eminente arquiteto executa operações com o análogo material do que virá a ser determinada adaptação espacial naquela cidade.

Antes de concluir o enunciado de mais esta questão, convém pensar em como estão trabalhando hoje muitos escultores, pintores e até escritores. E nāo se perca também de vista que dentro mesmo da operação dos modelos existem inúmeros submodelos. cada um com as suas técnicas e o seu correspondente saber específico.

\section{Conclusão}

Muitas outras questões foram sendo abertas pela investigação do processo de produção das adaptaçōes espaciais e de suas aglomerações, principalmente quando essa pesquisa refere-se às relações entre a forma dessas adaptações e aglomerações e a forma do espaço natural ou já adaptado. Do ponto de vista do método cabe reiterar que o trabalho científico é indutivo. Nāo se ponha ninguém a pensar para deduzir o mundo! Trata-se de examinar conjuntos cada vez mais amplos de objetos concretos para induzir proposiçōes gerais. Esses objetos concretos são as adaptações e suas aglomeraçōes, o espaço natural em todos os seus aspectos e as relaçōes que podem ser observadas entre a forma desse espaço e a forma daquelas adaptações e aglomeraçōes, e ainda, os instrumentos e as técnicas empregadas na sua construção.

De outro lado, é preciso compreender que a ciência é. como todas as outras atividades sociais, essencialmente cooperativa. De modo que não se trata de estabelecer um novo paradigma a cada nova tese de doutorado. Ja disse um famoso arquiteto que não se pode inventar uma nova arquitetura toda segunda-feira de manhã. Trata-se de delimitar um aspecto do sistema e procurar investigá-lo de maneira a acrescentar um pequeno, mas seguro elemento ao edifício do conhecimento. Por vezes, a simples comprovação de que determinada teoria, enunciada para outro conjunto de objetos-modelo, é válida para um outro conjunto de objetos, è trabalho suficiente. 
Como disse no início do presente trabalho, dirigi-o aos pós-graduandos em Arquitetura e Urbanismo. A minha intenção foi não apenas esclarecer alguns aspectos críticos de "O espaço natural e a forma urbana" como indicar algumas pistas que ficaram abertas naquela tese, além de conversar francamente sobre a problemática que se apresenta a quem se propōe a fazer uma tese ou dissertaçāo. A dificuldade provém da aceitaçāo da ausência de limites na área de investigaçāo que nos cabe, o que é comprovação indubitável de sua falta de especificidade. A concentraçāo dos; pesquisadores da FAU, nas questōes relativas às determinaçōes das formas das adaptaçōes espaciais e de suas aglomerações, considerando determinaçōes biológicas, sociais, culturais e tecnológicas, no que diz respeito ao espaço natural e aos espaços das cidades brasileiras, certamente nos permitirá construir uma teoria da arquitetura e do urbanismo, adequada à nossa inserçāo no processo de globalizaçāo, o qual não podemos evitar, mas do qual podemos ser sujeitos, e não meros objetos.

\section{Bibliografia}

Sendo o presente texto um comentário sobre o meu livro O espaço natural e a forma urbana, remeto o leitor à própria obra e à sua biblıografia:

SERRA, Geraldo. O espaço natural e a forma urbana. São Paulo: Nobel. 1987

A citação de Elie Faure foi retirada da sua famosa Histoire de l'Art, na edição Paris, Le Livre de Poche, 1976.

Outras obras relacionadas com o texto e que eventualmente podem ser recomendadas como "further reading" são:

HUME, David. A treatise of human nature. Penguin: Harmondsworth, 1969.

PAYOT Daniel. Le philosophe et l'architecte. Paris: Aubier, 1982.

PINTO. Alvaro Vieira. Ciência e existêncıa. Sāo Paulo: Paz e Terra. 1985.

ROSSI, Paolo. I filosofi e le machine 1400-1700. Milano: Feltrinelli, 1984.

SERRA, Geraldo. Urbanização e centralismo autoritário. São Paulo: Nobel-Edusp, 1991.

A natureza da pesquisa em arquitetura e urbanismo. In: A NATUREZA DA PESQUISA EM ARQUITETURA E URBANISMO. São Paulo. Anais. São Paulo: FAUUSP.

Teaching Architecture: a comparative analysis. In: Debate \& Dialogue - Architectural Design \& Pedagogy, Chicago: ACSA, 1989. 